\title{
FUNDAMENTO CONSTITUCIONAL DEL USO ALTERNATIVO DEL DERECHO
}

\author{
Por JOSE MARIA LASO PRIETO \\ Universidad de Oviedo
}

El artículo 9, apartados 1 y 2, del anteproyecto constitucional fue aprobado el 5 de julio de 1978 por el Congreso de Diputados. Obtuvo 314 votos a favor y dos abstenciones, quedando así redactado:

\section{Artículo 9}

1. Los ciudadanos y los poderes públicos están sujetos a la Constitución $\mathrm{y}$ al ordenamiento jurídico.

2. Corresponde a los poderes públicos promover las condiciones para que la libertad y la igualdad del individuo y de los grupos en que se integran sean reales y efectivas; remover los obstáculos que impidan o dificulten su plenitud, y facilitar la participación de todos los ciudadanos en la vida política, económica y social.

3. (..)

No es de prever que este texto sufra modificaciones apreciables en la discusión a la que el proyecto constitucional va a ser sometido en el Senado. Este texto, de los apartados 1 y 2 del artículo 9 de la Constitución de la nueva democracia española, puede ser interpretado por muchos ciudadanos en la línea de las platónicas declaraciones programáticas a que nos tienen habituados algunos textos constitucionales. Declaraciones en las que lo "programático» adquiere, generalmente, sentido peyorativo a causa de 
su nula incidencia en la propia vida cotidiana de esos ciudadanos. Es también frecuente que las fuerzas sociales retrógradas traten de mellar el filo de determinados artículos de los textos constitucionales, invocando ese carácter programático, en el sentido de equipararlo con utópicas buenas intenciones, para evitar su posible operatividad en los procesos de cambio social. Empero, sin negar que en los apartados 1 y 2 del artículo 9 citado se mantienen algunos de los rasgos tradicionales de los textos constitucionales programáticos, no por ello se agota la función de esta parte del Título Preliminar de la nueva Constitución española. Entre otras posibilidades, en ese texto puede basarse también el fundamento constitucional de un eventual uso alternativo del Derecho similar al que en los últimos años se viene efectuando en Italia.

En realidad el Derecho siempre se ha venido utilizando alternativamente; pero, en la mayoría de los casos, con un signo regresivo. Ahora se trata, por el contrario, de potenciar un uso del Derecho que sea verdaderamente alternativo de la utilización reaccionaria que del mismo se ha realizado por las distintas clases dominantes a lo largo de la Historia. Sus antecedentes actuales se remontan a los acontecimientos universitarios que singularizaron a Europa en 1968 y que en las Facultades de Derecho italianas sirvieron para cuestionar duramente los métodos de enseñanza tradicionales. Simultáneamente se va desarrollando un fuerte movimiento democrático entre jueces, secretarios judiciales, fiscales y magistrados que se expresa tanto en el plano asociativo como en el de las reuniones periódicas de juristas. Hitos importantes, en una dirección progresiva del Derecho italiano, quedan establecidos en una serie de Conferencias y Congresos de juristas. Así el Congreso que sobre Uso alternativo del Derecho tiene lugar en Catania del 15 al 17 de mayo de 1972 y el que acerca de "Técnicas Jurídicas y desarrollo de la persona» se celebra en mayo de 1973 en Bari. Finalmente las «Jornadas Jurídicas de Bolonia» (Abril-mayo de 1975) han posibilitado el balance de los resultados obtenidos en el proceso de concienciación democrática de los juristas.

Se trata, ante todo, de un amplio movimiento crítico en el que están inmersos los más prestigiosos juristas italianos que, habiendo adquirido conciencia de los estudios jurídicos se han fosilizado en el análisis de muchas instituciones ya superadas históricamente --mientras se ignoran los nuevos fenómenos originados por la actual etapa del desarrollo social-, concuerdan en la necesidad de un discurso crítico que suponga un uso alternativo del Derecho. Es decir, de una utilización del Derecho con un signo social diametralmente opuesto al tradicional. En definitiva, tal discurso crítico supone situarse en una nueva perspectiva superadora tanto de la supuesta 
neutralidad política del Derecho, como del dogmatismo sectario que lo instrumentaliza en un sentido miopemente partidista. Lo cual, por supuesto, tampoco supone renunciar al análisis del contenido de clase del Derecho.

Inicialmente, el movimiento de los juristas críticos italianos se planteó en un doble frente: el didáctico y el de la investigación. En el didáctico se trató, ante todo, de liberar a las Facultades de Derecho de la rutina académica que las desvinculaba de los problemas reales de la sociedad y degradaba sus enseñanzas al nivel de un memorismo ridículo. Con esa finalidad se trató de superar el estrecho marco de la lección magistral, mediante la proliferación de seminarios y clases prácticas, que, a su vez, se apoyaban en una concepción metodológica interdisciplinar. Sin embargo, como se reconoce en el interesante trabajo de Enrique Linde y Miguel Angel García Herrero titulado «La rebelión de los juristas» (1): «Sólo esporádicamente se alcanzó el buscado modelo interdisciplinar y crítico: profesores de distintas disciplinas, profesionales, estudiantes, trabajadores, trabajando conjuntamente, interconexión sobre temáticas de ciencias sociales, universalidad de los temas.r. Estas experiencias, que suponían una temática y una metodología didáctica innovadora eran dificilmente practicables, de una manera generalizada, en una Universidad de masas y acaban reproduciendo una vez más el modelo elitista. Pero si quizás los juristas críticos han fracasado en el plano de la didáctica, distinto ha sido el resultado en el plano de la investigación en el que esforzándose por superar la neutralidad y el dogmatismo, tratando de incorporar la historia, utilizando conceptos inéditos en los textos de Derecho como "Capitalismo» y «Marxismo», se abren lentamente, con dificultades a un mundo desconocido.»

Para los juristas críticos... «El Derecho sólo puede comprenderse y explicarse como un proceso histórico regido por determinados agentes sociales. Eliminando cualquier mistificación que olvide el estrecho entramado que conecta el Derecho con la estructura y descubriendo el nexo funcional que en él se expresa. Recuperando y evidenciando la relación que existe entre la realidad y los conceptos jurídicos a lo largo de la Historia, aprendiendo a leer de un modo distintos los textos legales (por ejemplo, comprender la Constitución italiana a través del fenómeno de la Resistencia) lo que significa la práctica del uso alternativo del Derecho, que no debe entenderse, como se ha hecho por algunos sectores, como la posibilidad de distintas interpretaciones de un texto legal a los efectos de ganar pleitos, sino que el uso alternativo debe venir referido, necesariamente, a los distintos modos

(1) Enrique Linde y Miguel Angel García, «La Rebelión de los juristas». Revista Triunfo, n. ${ }^{\circ} 673$ de 23 de agosto de 1975. 
y posibilidades de organizar las relaciones sociales.» Todas estas aspiraciones se concretan en la propuesta de una crítica materialista de la categoría jurídica, del estudio del Derecho en cuanto a norma o volición social reguladora, y, al mismo tiempo, en cuanto a institución social articulación de la realidad misma.

\section{El uso alternativo del Derecho en EsPaÑa}

La reciente publicación en España de tres obras dedicadas al uso alternativo del Derecho (2), las Jornadas que sobre el mismo tema se han desarrollado del 7 al 10 de febrero de 1977 en la Universidad de Granada, el funcionamiento en la Universidad de Oviedo de un Seminario Interdisciplinar que, utilizando técnicas de uso alternativo del Derecho, ha abordado durante los cursos 1975-76 y 1976-77, los temas de la reforma del Título Preliminar del Código Civil y de la reforma del Derecho de Familia, así como la realización, en diciembre de 1977, por el Colegio de Abogados de Bilbao, de unas Jornadas Jurídicas Laboralistas con una fuerte incidencia insalternativista, demuestran que en nuestro país comienzan a desarrollarse corrientes de interés por esta innovadora teoría jurídica italiana.

Ahora bien, el uso alternativo del Derecho se caracteriza, entre otros, por el rasgo de que en su desarrollo están indisolublemente ligados teoría y praxis. En consecuencia, el interés teórico que por el mismo se ha suscitado en el país requería, como complemento indispensable, la creación de las condiciones precisas para su práctica jurídica. Es decir, un fundamento constitucional que posibilitase su ejercicio. En ese sentido Italia nos ofrecía también la necesaria pauta, ya que en dicho país la praxis iusalternativista tiene un sólido fundamento constitucional. Por otra parte, sin pretender efectuar una homologación simplista al modelo jurídico-politico italiano, es evidente el interés que para nosotros adquieren las experiencias muy diversificadas que proceden de esa península mediterránea.

Previsiblemente, en los años inmediatos, vamos a alcanzar en España

(2) Pietro Barcellona y Giuseppe Coturi, El Estado y los juristas. Editorial Fontanella. Barcelona, 1976.

Barcellona, Hart y Mückenberger, La formación del jurista (Capitalismo monopolista y cultura juridica). Editorial Civitas. Madrid, 1977. Nicolás López Calera. Modesto Saavedra López, Perfecto Andrés Ibáñez, Sobre el uso alternativo del Derecho. Fernando Torres, editor. Valencia, 1978. Por último, aunque esté redactado desde la perspectiva más amplia de Justicia Democrática, también puede considerarse como adscrita al uso alternativo del Derecho la obra: Qué es la Justicia Democrática, de Plácido Fernández Viagas. Editorial La Gaya Ciencia. Madrid, 1977. 
niveles de desarrollo económico y social muy similares a los italianos. Por consiguiente, gran parte de nuestra problemática tenderá a homologarse con la italiana. Al menos en sus líneas generales, y con las diferencias de matiz específicas del respectivo proceso histórico. Con ello podremos los españoles utilizar un rico acervo de experiencias sociales y elaboraciones científicas que hasta ahora - por el anacronismo histórico del régimen franquista - nos habian resultado inasequibles.

Italia nos aventaja, sobre todo, por el hecho relevante de haberse liberado del fascismo en los años 1944-45. Como consecuencia de esa liberación, y del espíritu de la resistencia antifascista que todavía imperaba en el país, la Constitución de la República Italiana, promulgada el 27 de diciembre de 1947, se ha consagrado como una de las más avanzadas de nuestra época. Y no sólo en el plano formal, ya que las declaraciones programáticas de otras Constituciones también lo son, sino sobre todo porque, con vẹrdadero carácter innovador, en su artículo $3 .^{\circ}$ se ha resuelto técnicamente el problema de lograr un resorte normativo contra los obstáculos que la inercia jurídica opone habitualmente al cambio social. $\mathrm{Y}$ aunque es evidente que, durante los últimos años, no se ha obtenido pleno rendimiento de ese consolidador jurídico del cambio social, no es menos obvio que las causas retardatarias del fenómeno se pueden considerar ya superadas. Han estribado, fundamentalmente, en el clima asfixiante de la guerra fría y de la consiguiente omnímoda hegemonía del Partido de la Democracia Cristiana. Todo induce, por lo tanto, a suponer, con sólidos fundamentos de previsibilidad científica, que, en las nuevas condiciones fácticas del compromiso histórico, Italia se encuentra en los umbrales de profundas transformaciones sociales muy aleccionadoras para nosotros.

Juridicamente, el fundamento constitucional del uso alternativo del Derecho es muy sólido en Italia. Así en el mencionado artículo $3 .^{\circ}$ de la Constitución se declara:

\section{Artículo 3}

1. Todos los ciudadanos tienen idéntica dignidad social y son iguales ante la ley, sin distinción de sexo, raza, idioma, religión, opiniones políticas, condiciones personales o sociales.

2. Incumbe a la República remover los obstáculos de orden económico y social que, limitando de hecho la igualdad de los ciudadanos impidan el pleno desarrollo de la persona humana y la efectiva participación de todos los trabajadores en la organización política, económica y social del país. 
De una lectura atenta del texto del artículo se deduce claramente el carácter imperativo que se ha pretendido proporcionar a su redacción. Si bien en el primer apartado se mantiene todavía la forma tradicional de las denominadas "normas programáticas» - aunque con un contenido muy amplio y diversificado- en el apartado segundo se atribuye al Estado una misión social transformadora destinada a lograr la efectividad de la igualdad. Con ello la Constitución Italiana se sitúa a la vanguardia de la corriente política actual que trata de consagrar los derechos constitucionales de tal modo que pasen a ser derechos efectivos para la gran mayoria de la población. Desde esa perspectiva se trata también de consolidar, en una primera y dinámica síntesis de inspiración togliattiana, las libertades políticas obtenidas por la burguesía revolucionaria en el siglo XIX y las libertades sociales conquistadas por las masas populares en el siglo XX.

Debe subrayarse también -en contraste con la mayoría de las Constituciones burguesas tradicionales- la gran precisión que el texto constitucional italiano adquiere, al concretar que son «obstáculos de orden económico y social» los que limitan de hecho la igualdad de los ciudadanos. $\mathrm{Y}$, en una perspectiva todavía socialmente más avanzada, el que se atribuya a la República como objetivo el logro de la «efectiva participación de todos los trabajadores en la organización política, económica y social del país». En efecto, en el texto constitucional italiano, ya no se trata de una declaración programática, sin correspondencia real en la estructura sociológica del país, similar a la proclamación de España como «República de Trabajadores» en la Constitución de 1931, sino de un mandato específico a los órganos del Estado destinado a promover una efectiva participación de los trabajadores en la estructuración y gestión de la nación.

Desde esa misma perspectiva, del Derecho Constitucional Comparado, resulta también interesante el contraste que en este aspecto puede efectuarse entre la Constitución Italiana y la portuguesa. La Constitución de Portugal - promulgada el 2 de abril de 1976- se inspira explícitamente en el espíritu del Movimiento de las Fuerzas Armadas que derrocó el 25 de abril de 1974 a la dictadura caetanista-salazarista. En consecuencia, su texto está impregnado de una concepción progresista que pretendía apoyarse en el Consejo de la Revolución —como cúspide colegiada del Movimiento de las Fuerzas Armadas- para constitucionalizar la posibilidad de que el país lusitano pueda iniciar en un futuro próximo la vía portuguesa al socialismo. De ahí los reiterados intentos de la renaciente derecha portuguesa de plantear el problema de la revisión constitucional.

En el aspecto concreto que en este trabajo nos interesa -el de como resolver técnicamente, en el plano constitucional, el problema de lograr 
un resorte normativo contra los obstáculos que la inercia juridica opone habitualmente al cambio social- debemos fijarnos inicialmente en el artículo 13 de la Constitución de la República Portuguesa, que consagra el principio de igualdad, y que constituye el homólogo del art. $3 .^{\circ}$ de la Constitución Italiana:

\section{ARTículo $13 .^{\circ}$ (PRINCIPIO De IGUALDAD)}

1. Todos los ciudadanos tienen la misma dignidad social y son iguales ante la ley.

2. Nadie puede ser privilegiado, beneficiado, perjudicado, privado de cualquier derecho o exento de cualquier deber en razón de su ascendencia, sexo, raza, lengua, territorio de origen, religión, convicciones políticas e ideológicas, instrucción, situación económica o condición social.

Evidentemente se trata de una muy amplia, y muy precisa, proclamación del principio de igualdad que supera incluso idéntica proclamación en la Constitución Italiana. Sin embargo, en la perspectiva del uso alternativo del Derecho, no proporciona una base constitucional tan rigurosa. Carece de un mandato imperativo explícito a los órganos del Estado tendente a atribuirles la misión de remover los obstáculos de orden económico y social que limitan la efectividad de ese principio de igualdad que tan rotundamente se propugna. Ahora bien, no sería justo limitar la comparación entre ambas Constituciones al contraste de dichos artículos. En la Constitución Portuguesa se define ya a Portugal, desde su art. $1^{\circ}$, como... «una República soberana, basada en la dignidad de la persona humana y en la voluntad popular, y empeñada en su transformación en una sociedad sin clases». Definición que se completa en su art. 2.1 -que lleva por epigrafe Estado democrático y transición al socialismo- al precisar que «la República Portuguesa es un Estado democrático, basado en la soberanía popular..., que tiene por objetivo asegurar la transición hacia el socialismo mediante la creación de condiciones para el ejercicio democrático del poder de las clases trabajadoras». A su vez estas normas programáticas generales se complementan con otras más específicas que, debidamente aplicadas, supondrian una transformación revolucionaria de la estructura social de Portugal:

Art. $99^{\circ}$ (TAREas fundamentales del Estado)

Son tareas fundamentales del Estado:

a) 
b)

c) Socializar los medios de producción y la riqueza, a través de formas adecuadas a las características del presente período histórico, crear las condiciones que permitan promover el bienestar y la calidad de la vida del pueblo, especialmente de las clases trabajadoras, y abolir la explotación y la opresión del hombre por el hombre.

Art. $10 .^{\circ}$ (Proceso Revolucionario)

1.

2. El desenvolvimiento del proceso revolucionario impone, en el plano económico, la propiedad colectiva de los principales medios de producción.

En este trabajo no podemos - por obvias limitaciones de espacioentrar en el análisis del proceso político de Portugal. Por consiguiente no podemos pronunciarnos acerca de la viabilidad de una posible ruta portuguesa al socialismo basada, jurídicamente, en esas premisas constitucionales. De lograrse, haria superfluo el uso alternativo del Derecho. Este sólo tiene sentido cuando - por diversas causas - no es posible a corto plazo un proceso de transformación revolucionaria de la sociedad. Como ya sosteniamos, en nuestro trabajo «Función del Derecho en el cambio social» (3), en una perspectiva más netamente política es obvio que si el Derecho no puede sustituir a la revolución, como sujeto activo del cambio social radical impuesto por la actuación de las masas, tampoco puede afirmarse convincentemente que la revolución sea factible en todo lugar y momento. De ahí la interminable polémica, teórica y práctica, acerca de las condiciones objetivas y subjetivas necesarias para su realización. Se hace, en consecuencia, necesario contribuir a la dinamización de la sociedad por otros medios. Entre ellos, asimismo, desempeñan una función importante las reformas sociales promulgadas legislativamente y la lenta, pero creciente, socialización del fundamento interpretativo de muchas sentencias judiciales. Se trata de una evolución social gradualista, pausada y no siempre irreversible. Además, la propia lentitud de la evolución reformista propicia que se intente investigar la factibilidad de otros medios. De esta necesidad ha surgido precisamente uno de los impulsos que ha originado el movimiento para un uso alternativo del Derecho.

Evidentemente si la vía hacia el socialismo en Portugal se estanca -como

(3) José Maria Laso, «Función del Derecho en el cambio social», en «Argumentos», n. 7 . Diciembre de 1977. Págs. 15 a 17. 
parece muy probable - y no se produce una involución o una reforma constitucional regresiva - como ya es más probable - en la Constitución portuguesa, considerada globalmente, hay base más que suficiente para que en el país lusitano sea factible un uso alternativo del Derecho progresista. En ello precisamente estriba el núcleo esencial de una posición iusalternativista. Como muy bien sintetiza el profesor Elias Díaz (4) -en una nota a pie de página a su obra "Legalidad-Legitimidad en el Socialismo Democrático»- «se trata de hacer uso del Derecho en forma muy diferente de la que ha sido tradicional: ese es, puede decirse, el propósito central de tales posiciones alternativistas. Quizá fundamentalmente en dos sentidos: 1) El de asumir el ordenamiento jurídico en su totalidad, (el subrayado es nuestro) aplicando la legislación ordinaria de modo que permita extraer de ella todas las posibilidades progresivas que se deriven, por ejemplo, de su interpretación desde la legislación constitucional (caso del art. 3 de la Constitución italiana); 2) en el de desenmascarar el carácter supuestamente apolítico y neutralista del Derecho, desentrañando, por tanto, todas sus potencialidades como instrumento realmente democratizador, que realice una justicia no partidista sino entendida como creadora de libertad real e igual para todos».

Por otra parte, esa posibilidad iusalternativista de la Constitución Portuguesa se refuerza por la introducción (en sus art. 279 y 280) de las figuras de la inconstitucionalidad por omisión y por acción. Concretamente, respecto a la omisión, el art. 279 establece: "Cuando la Constitución no llegue a ser cumplida por omisión de las medidas legislativas necesarias para hacer ejecutivas las normas constitucionales, el Consejo de la Revolución podrá recomendar a los órganos legislativos competentes que las promulguen en un tiempo razonable.»

Sin duda, después de esta amplia glosa del fundamento constitucional del uso alternativo del Derecho en Italia y Portugal, puede producirse la impresión de que en nuestra Constitución ese fundamento es mucho más débil. Sin embargo, aún reconociendo que el artículo 9 (apartados 1 y 2), directamente inspirado en el artículo 3 de la Constitución Italiana, ha sufrido una clara atenuación de la rotunda especificidad que caracteriza el texto italiano, no por ello deja de constituir ese fundamento constitueional necesario para la práctica iualternativista. En ese sentido ha sido valorado, justamente, por los juristas críticos italianos. Estos resaltan también que, para la debida perspectiva alternativista, debe además ser situado en el contexto global del proyecto constitucional. Así debería ser interrelacionado

(4) Elias Díaz, Legalidad-Legitimidad en el Socialismo Democrático. Editorial Civitas. Materiales, 1978, pág. 54 . 
positivamente con los artículos $1,7,10,13,19,21,23,24,26,27,28$, $30,32,33,34,36,38,39,40,41,43,44,45,46,47,48,49,152$ y conexos. Por el contrario, constituye un elemento muy negativo de nuestro proyecto de Constitución el hecho de que en el artículo 119, aún reconociendo el derecho de asociación profesional de jueces, magistrados, secretarios judiciales y fiscales, les niegue el derecho a la sindicación y a la militancia en partidos políticos. Se trata de una limitación en sus derechos ciudadanos que no tiene precedente en los textos constitucionales de los países democráticos. Con el pretexto de asegurar la necesaria independencia de la Justicia se ha relegado a estos funcionarios a la condición de ciudadanos de segundo orden. Empero es obvio que tras ese pretexto formal se ocultan los intereses sociales que tratan - tras la fachada de una supuesta apoliticidad- de mantener a toda costa el carácter clasista del aparato judicial. Así lo corrobora también de forma elocuente el que, al votarse este artículo, U.C.D. se desmarcase del consenso negociado con los partidos de izquierda para votar con Alianza Popular. Con ello se hizo precisa una transacción que, al menos, obtuvo el reconocimiento constitucional del derecho de asociación profesional de dicho personal.

El problema se va a suscitar en España fundamentalmente en el terreno de la interpretación judicial. En ese sentido Italia es también paradigmática. Durante todo un período histórico han coexistido en ese país considerables residuos de la legislación fascista con una Constitución democrática más avan ada. Como es lógico los problemas de interpretación han sido constantes, Jando lugar a fuertes choques entre el Tribunal de Casación (equivalente a nuestro Tribunal Supremo y dominado por la Magistratura más conservadora) y el Tribunal Constitucional que, generalmente, tiende a situarse en una perspectiva democrática. Como consecuencia ha quedado evidenciada la falacia de la supuesta neutralidad política de la judicatura y ello ha producido efectos catárticos en un sector importante del personal judicial.

En Italia la Magistratura que remonta su experiencia asociativa a comienzos de siglo, se había mantenido tradicionalmente en las posiciones de un supuesto apoliticismo. De ahí que a través de ese proceso catártico -que incide fundamentalmente en las nuevas promociones judiciales- surge, en el seno de la conservadora "Asociación Nacional de Magistrados» (ANMI), el movimiento de Magistratura Democrática (M.D.) que durante los años sesenta - como precedente del uso alternativo del Derecho - «estuvo dirigido a la acomodación de la legislación ordinaria y la práctica judicial a los dictados de la norma constitucional, siendo medio privilegiado aunque no exclusivo el incidente de constitucionalidad planteado contra toda clase de disposiciones tenidas por contraventoras de aquella... Por otra parte, 
un profundo sentido garantista de la función, decididamente asumido por M.D., ha constituido en multitud de ocasiones el más firme apoyo a nuevas formas sociales de oposición y de lucha que se debatían entre su reconocimiento implícito en la legalidad constitucional y el carácter restrictivo de la normativa concreta de inspiración conservadora o francamente reaccionaria, aún vigente en amplios sectores del ordenamiento. Este fenómeno ha sido bautizado como suplencia de la magistratura, con lo que, ha escrito Salvatore Senese en fecha reciente, se quiere aludir a una intervención de la misma en conflictos pólíticos o sociales o, más en general, en problemáticas socioeconómicas que bastante más correctamente deberían encontrar su propia mediación y tratamiento en sedes políticamente responsables y como consecuencia de una mediación que a ellas incumbe» (5).

En tal sentido - según opinión del juez D. Perfecto Andrés Ibáñez que compartimos- es sumamente ilustrativo, de la actitud de $M$. D. frente a los problemas específicos del sector, lo acordado en las Conclusiones del Congreso de Florencia (mayo 1973), que señalan como tareas fundamentales de la corriente: a) la valoración de los aspectos democráticos igualitarios de la Constitución y la defensa intransigente de las libertades constitucionales y de la legalidad democrática; b) la desmitificación de la imagen tradicional del juez neutral, que oculta el papel clasista de la función judicial y la reafirmación del significado garantista de la independencia de la magistratura respecto a las acciones políticas del ejecutivo (...) c) la adecuación de la acción política de M.D. a las conquistas realizadas a través de las luchas sociales, en el sentido de hacer imposible el intento de neutralizar mediante la acción judicial las conquistas obtenidas a nivel normativo mediante la lucha de clases.

Para completar esta panorámica de la incidencia del fundamento constitucional del uso alternativo del Derecho en la problemática jurídica italiana -que nos proporciona experiencias y elaboraciones teóricas que nos van a ser muy útiles en nuestro futuro inmediato- conviene tener en cuenta que; en el último Congreso de Rímini, 'celebrado del 3 al 5 de abril de 1977 por Magistratura Democrática, en torno al tema "Crisis institucional y renovación democrática de la Justicia», se han producido fuertes polémicas políticas, desde distintas opciones partidistas de izquierdas, que han afectado también al tema del uso alternativo del Derecho. Así Pietro Barcellona se ha pronunciado recientemente en el sentido de que «el uso alternativo del Derecho, en cuanto a fungibilidad y manipulabilidad del texto normativo,

(5) Perfecto Andrés Ibáñez, “La izquierda judicial italiana». Materiales. núm. 9. Mayo-junio 1978. Págs. 41 y sig. 
es ahora ya un concepto superado, presentando dos limites: uno de carácter teórico, porque el mismo permanecerá siempre en el álveo de la interpretación; y uno de carácter práctico, en cuanto aseguraria a los magistrados un papel defensivo y reductivo en función suplente. Posteriormente, el propio Barcellona ha sostenido en Rinascitá que «la jurisprudencia alternativa, ligada a una visión de la ciencia jurídica que se identificaba con la "interpretación" de la norma, tuvo su razón de ser en una fase de actitud defensiva del movimiento obrero y democrático italiano. En esta situación un sector de la magistratura se vio en la necesidad de asumir, en apoyo del orden democrático, la defensa de las opciones políticas y movimientos en las áreas institucionales correspondientes. Sin embargo, esta función "suplente" ha dejado de ser necesaria ahora, cuando se asiste a "una dilatada hegemonía de la clase obrera" que se traduce en la modificación de los aparatos institucionales y creación de nuevos instrumentos capaces de expresar esa hegemonía. (...) Por eso la cuestión de la dirección de la sociedad no puede ser reabsorbida en el momento jurisdiccional; en la fase actual el acento está puesto más que sobre el momento jurisdiccional en el de la producción normativa ya que es precisamente el sistema de las fuentes el que se va modificando (...) y es por lo que estamos en una fase más avanzada respecto al uso "alternativo" del Derecho".

Empero, por nuestra parte, consideramos que es muy acertada la posición de $\mathrm{P}$. Andrés lbáñez cuando precisa: «Al anterior punto de vista cabe objetar que si es cierto que nunca se ha pensado por los juristas alternativos sustituir con su práctica la lucha política, lo que sería ciertamente ridículo, también lo es que el uso "alternativo" expresa un planteamiento del Derecho lo suficientemente radical como para que no pueda ser desplazado por una modificación de la coyuntura que, si es importante por lo que conlleva de afianzamiento y progreso de las fuerzas tradicionales de izquierda, está aún muy lejos de traducirse en un efectivo control institucional y un cambio cualitativo del marco jurídico» (6). Por desgracia, en España estamos todavía más lejos de esa situación y, en consecuencia, se puede prever una prolongada operatividad al uso alternativo del Derecho cuyo fundamento constitucional nos hemos esforzado en explicitar.

(6) Op. cit., págs. 54 y 55 . 


\section{BIBLIOGRAFIA}

A continuación facilitamos una pequeña bibliografia de los trabajos sobre uso alternativo del Derecho asequibles en castellano.

EnRique Linde y Miguel ANGel García: La Rebelión de los juristas, revista TRIUNFO, n. ${ }^{\circ} 673$ de 23 de agosto de 1975.

Pietro Barcellona y Giuseppe Coturri: El Estado y los juristas, editorial Fontanella,. Barcelona, 1976.

BARCELlONA, HART y MüCKENBERGer: La formación del jurista (Capitalista monopolista y cultura jurídica). Editorial Civitas. Madrid, 1977.

Nicolás López Calera, Modesto SaAvedra López, Perfecto Andrés Ibáñez: Sobre el uso alternativo del Derecho, Fernando Torres, editor. Valencia, 1978.

Plácido Fernández Viagas: Qué es la Justicia Democrática, Editorial La Gaya Ciencia. Madrid, 1977.

Elías DíAz: Legalidad-Legitimidadenel Socialismo Democrático, EditorialCivitas. Madrid, 1978.

Perfecto ANDrés IbÁÑez: Para una práctica judicial alternativa, Anales de la cátedra Francisco Suárez. Universidad de Salamanca, n. ${ }^{0} 16,1976$.

Manuel Peris: Juez, Estado y Derechos Humanos, Fernando Torres, editor. Valencia, 1976.

Ramón García Cotarelo: El derecho de resistencia, revista Argumentos n. ${ }^{\circ} 13$, junio de 1978.

José MARÍA LASE PRIETO: Hacia un nuevo uso alternativo del Derecho, revista Argumentos, n. ${ }^{\circ}$, julio 1977.

José María laso Prieto: Función del Derecho en el cambio social, revista Argumentos, n. ${ }^{\circ}$ 7, diciembre, 1977.

José María Laso Prieto: Sobre el uso alternativo del Derecho, revista El Basilisco, n. ${ }^{\circ}$, mayo-junio, 1978. (Con el mismo título se publica un extracto del trabajo en la revista Argumentos, $\mathrm{n}^{\circ} 13$, junio 1978.)

Manuel Rico LaRa: Sobre el uso alternativo del Derecho, Boletin de Información del Ministerio de Justicia, n. ${ }^{\circ} 1.130$, Madrid, 5 mayo 1978. 